\title{
Clinicopathological features of senile systemic amyloidosis: an ante- and post-mortem study
}

\author{
Mitsuharu Ueda ${ }^{1, *}$, Yoko Horibata ${ }^{1, *}$, Makoto Shono $^{1}$, Yohei Misumi ${ }^{1}$, Toshinori Oshima ${ }^{1}$, \\ $\mathrm{Yu} \mathrm{Su}{ }^{1}$, Masayoshi Tasaki ${ }^{1}$, Satoru Shinriki ${ }^{1}$, Satomi Kawahara ${ }^{1}$, Hirofumi Jono ${ }^{1}$, \\ Konen Obayashi ${ }^{1}$, Hisao Ogawa ${ }^{2}$ and Yukio Ando ${ }^{1}$ \\ ${ }^{1}$ Department of Diagnostic Medicine, Graduate School of Medical Sciences, Kumamoto University, \\ Kumamoto, Japan and ${ }^{2}$ Department of Cardiology, Graduate School of Medical Sciences, Kumamoto \\ University, Kumamoto, Japan
}

\begin{abstract}
Senile systemic amyloidosis is a common age-related amyloidosis that involves accumulation of wild-type transthyretin, with cardiac dysfunction being a predominant result. The importance of obtaining an accurate diagnosis of senile systemic amyloidosis has been increasingly recognized, so that novel treatments are being developed. However, the clinicopathological features of senile systemic amyloidosis remain to be completely understood. Here, we evaluated cardiac specimens from 181 consecutive post-mortem cases older than 40 years, including 6 cases of senile systemic amyloidosis, and 5 cases of familial amyloidotic polyneuropathy, which is a hereditary systemic amyloidosis caused by mutant forms of transthyretin. Furthermore, we studied ante-mortem clinicopathological findings of 11 senile systemic amyloidosis cases, in which 9 cases underwent gastrointestinal tract biopsy and/or subcutaneous tissue biopsy, at Kumamoto University Hospital. Of the autopsied cases of elderly Japanese (older than 80 years), $12 \%$ had senile systemic amyloidosis, with the percentage increasing with age. The occurrence of senile systemic amyloidosis in elderly Japanese patients was lower than that in previous reports, which suggests that a genetic background and/or environmental factor(s) may have important roles in the occurrence of senile systemic amyloidosis. Transthyretin amyloid deposits in familial amyloidotic polyneuropathy cases developed mainly in the pericardium and the surrounding muscle fascicles, whereas in cases with senile systemic amyloidosis the transthyretin amyloid deposits had a patchy plaque-like shape and developed mainly inside the ventricular wall. Biopsies from senile systemic amyloidosis patients evidenced amyloid deposits in $44 \%(4 / 9)$ of gastrointestinal tract and subcutaneous tissue samples combined. As myocardial biopsy may be dangerous for elderly people, the use of a combination of gastrointestinal tract and subcutaneous tissue biopsies may make diagnosis of senile systemic amyloidosis easier.
\end{abstract}

Modern Pathology (2011) 24, 1533-1544; doi:10.1038/modpathol.2011.117; published online 5 August 2011

Keywords: aging; amyloidosis; biopsy; diagnosis; familial amyloidotic polyneuropathy; senile systemic amyloidosis; transthyretin

Amyloidosis is characterized by the presence of extracellular deposits of insoluble amyloid fibrils. ${ }^{1,2}$ It is also classified as one of the protein conformational diseases, also called proteinopathies, in which specific proteins accumulate and affect organ functions. ${ }^{3}$ Thus far, 27 different protein precursors

Correspondence: Professor Y Ando, MD, PhD, Department of Diagnostic Medicine, Graduate School Medical Sciences, Kumamoto University, 1-1-1 Honjo, Kumamoto 860-8556, Japan.

E-mail: andoy709@kumamoto-u.ac.jp

*These authors contributed equally to this work.

Received 25 January 2011; revised 25 May 2011; accepted 31 May 2011; published online 5 August 2011 of amyloid fibrils have been identified as the cause of different kinds of amyloidosis, such as Alzheimer's disease, prion disease, and type 2 diabetes. ${ }^{4}$ In those amyloidoses, several clinical features, such as aging, genetic mutation, inflammation, and tumors, can stimulate disease-causing polymerization of functional soluble proteins in the body. ${ }^{1,2}$

Senile systemic amyloidosis, in which wild-type transthyretin forms amyloid deposits in various tissues, is an age-related nonhereditary systemic amyloidosis and affects mainly cardiac functions in elderly people. ${ }^{5,6} \mathrm{~A}$ few post-mortem studies carried out in the United State and European countries 
reported that the prevalence of senile systemic amyloidosis was $22-25 \%$ in patients older than 80 years. $^{7-9}$ However, the prevalence of senile systemic amyloidosis in other populations, such as those in other Asian countries, remains to be elucidated.

Mutant forms of transthyretin cause familial amyloidotic polyneuropathy, which is a hereditary amyloidosis. ${ }^{10}$ To date, $>120$ transthyretin mutations have been identified, most of which lead to development of familial amyloidotic polyneuropathy; transthyretin Val30Met is the most common disease-causing transthyretin mutation in the world. ${ }^{11,12}$ Although clinical disorders of typical familial amyloidotic polyneuropathy patients, including peripheral neuropathy, autonomic dysfunction, renal dysfunction, gastrointestinal disorders, and ocular manifestations, are different from those of patients with senile systemic amyloidosis, several transthyretin variants such as transthyretin Val122Ile cause a cardiac amyloidosis that mimics senile systemic amyloidosis. ${ }^{13}$

The importance of accurate diagnosis of senile systemic amyloidosis has been increasingly recognized, and a novel specific transthyretin stabilizer, tafamidis, has been developed and is undergoing phase II and III clinical trials. ${ }^{14}$ This chemical compound reportedly prevented dissociation of native transthyretin tetramers into monomers, which is a key factor in promoting amyloid fibrillogenesis. ${ }^{15}$ Effective medical treatment of patients with transthyretin amyloidosis requires an accurate diagnosis with the use of various examinations, including histopathology, echocardiography, scintigraphy, genetic testing, mass spectrometry, and serum protein analyses. ${ }^{6}$ Histopathological examinations have a critical role in obtaining direct evidence of amyloid deposits and determining the type of amyloid-causing protein. As the heart is the most commonly affected organ, myocardial biopsy is thought to be the most sensitive method for detecting amyloid deposits in patients with senile systemic amyloidosis, but this type of biopsy is too invasive and carries a risk of complications, especially for elderly patients. In patients with other types of systemic amyloidosis, less invasive biopsy, such as of the gastrointestinal tract, labial salivary gland, and subcutaneous tissue, has been preferred, because amyloid deposits in those tissues occur early in the course of disease. ${ }^{1}$ However, the histopathological features of amyloid deposits in systemic tissues in senile systemic amyloidosis remain to be clarified.

In this study, we investigated the clinicopathological features of senile systemic amyloidosis, including the occurrence of senile systemic amyloidosis and the distribution of amyloid deposits. We found major histopathological differences between senile systemic amyloidosis and familial amyloidotic polyneuropathy. We also describe how to perform histopathological examinations to achieve an accurate diagnosis of senile systemic amyloidosis.

\section{Patients and methods}

\section{Patients}

To determine the occurrence of cardiac amyloidosis, we evaluated cardiac specimens from 181 consecutive post-mortem cases. Specimens were available for patients who had died at the age of 40 years or older (11 patients in their forties, 35 in their fifties, 44 in their sixties, 65 in their seventies, 20 in their eighties, 5 in their nineties, and 1 centenarian) and who were autopsied at Kumamoto University Hospital between January 2001 and March 2008, which included 5 cases of familial amyloidotic polyneuropathy who had died at the age of 40 years or older. Patient selection process for post-mortem studies was shown schematically in Figure 1. Patients' profiles of senile systemic amyloidosis and familial amyloidotic polyneuropathy were described in Table 1. To determine the distribution

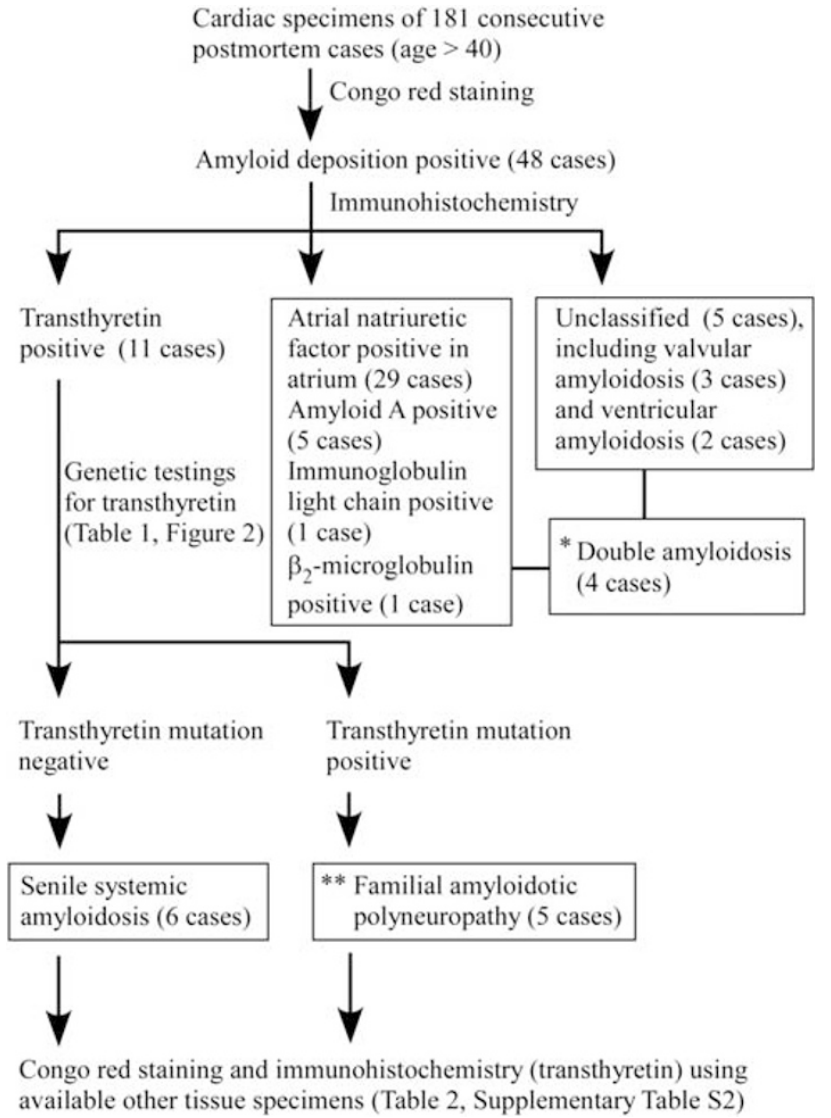

Figure 1 Schematic presentation of patient selection for postmortem studies. *Four cases of double amyloidosis include amyloid A+atrial natriuretic factor in atrium (two cases), $\beta_{2}$-microglobulin + unclassified valvular amyloidosis (one case), and atrial natriuretic factor in atrium + unclassified ventricular amyloidosis (one case). ${ }^{*}$ Detailed histopathological findings of familial amyloidotic polyneuropathy cases were also showed in Supplementary Table S2. 
Table 1 Clinical features for 6 autopsied and 11 ante-mortem biopsied cases of senile systemic amyloidosis and for 6 autopsied cases of familial amyloidotic polyneuropathy

\begin{tabular}{|c|c|c|c|c|c|c|c|c|c|}
\hline Case no. & $\begin{array}{l}\text { Transthyretin } \\
\text { gene }\end{array}$ & $\begin{array}{c}\text { Molecular mass } \\
\text { of serum } \\
\text { transthyretin } \\
\text { (Da) }\end{array}$ & $\begin{array}{c}\text { Age } \\
\text { (year) }\end{array}$ & Sex & $\begin{array}{l}\text { Heart weight } \\
(g)\end{array}$ & $\begin{array}{l}R V \text { thickness } \\
(\mathrm{mm})\end{array}$ & $\begin{array}{l}\text { LV thickness } \\
\quad(\mathrm{mm})\end{array}$ & $\begin{array}{l}\text { Main causes } \\
\text { of death }\end{array}$ & $\begin{array}{l}\text { Histopathological features of transthyretin } \\
\text { amyloid deposits in the } L V \text { wall }\end{array}$ \\
\hline \multicolumn{10}{|c|}{ Senile systemic amyloidosis (autopsied cases) } \\
\hline A-case 1 & Wild type & $\mathrm{NE}$ & 73 & $\mathrm{M}$ & 830 & 5 & $\mathrm{NE}$ & Sepsis & Patchy plaque-like shape (small) \\
\hline A-case 2 & Wild type & $\mathrm{NE}$ & 73 & $\mathrm{M}$ & 550 & 2 & 15 & $\begin{array}{l}\text { Interstitial } \\
\text { pneumonia, } \\
\text { pneumothorax, } \\
\text { pulmonary } \\
\text { hemorrhage }\end{array}$ & Patchy plaque-like shape (small to large) \\
\hline A-case $3^{\mathrm{a}}$ & Wild type & 13761 & 75 & $\mathrm{M}$ & 750 & 7 & 20 & $\begin{array}{l}\text { Cardiac failure, } \\
\text { sepsis }\end{array}$ & $\begin{array}{l}\text { Combined patchy deposits (diffuse } \\
\text { pericellular deposition) }\end{array}$ \\
\hline A-case 4 & Wild type & $\mathrm{NE}$ & 83 & $\mathrm{~F}$ & 210 & 2 & 10 & $\begin{array}{l}\text { Carcinomatous } \\
\text { peritonitis }\end{array}$ & Patchy plaque-like shape (small to large) \\
\hline A-case 5 & Wild type & $\mathrm{NE}$ & 93 & $\mathrm{M}$ & 400 & 4 & 15 & Cardiac failure & Patchy plaque-like shape (small) \\
\hline A-case 6 & Wild type & $\mathrm{NE}$ & 102 & $\mathrm{~F}$ & $\mathrm{NE}$ & $\mathrm{NE}$ & $\mathrm{NE}$ & Cardiac failure & Patchy plaque-like shape (small to large) \\
\hline Average & & & 83.2 & & 548.0 & 4.0 & 15.0 & & \\
\hline S.d. & & & 12.0 & & 253.2 & 2.1 & 4.1 & & \\
\hline \multicolumn{10}{|c|}{ Senile systemic amyloidosis (biopsied cases) } \\
\hline B-case $1^{\mathrm{b}}$ & Wild type & 13761 & 56 & $\mathrm{M}$ & NA & $\mathrm{NE}$ & $19.4^{\mathrm{c}}$ & Alive & Patchy plaque-like shape (moderate) \\
\hline B-case $2^{\mathrm{b}}$ & Wild type & 13761 & 69 & $\mathrm{M}$ & NA & $\mathrm{NE}$ & $15.8^{\mathrm{c}}$ & Alive & Patchy plaque-like shape (small) \\
\hline B-case $3^{\mathrm{b}}$ & Wild type & 13761 & 70 & $\mathrm{M}$ & NA & $\mathrm{NE}$ & $24.9^{\mathrm{c}}$ & Alive & $\mathrm{NE}$ \\
\hline B-case $4^{\mathrm{b}}$ & Wild type & 13761 & 71 & $\mathrm{M}$ & NA & $\mathrm{NE}$ & $11.9^{\mathrm{c}}$ & Alive & Patchy plaque-like shape (moderate) \\
\hline B-case $5^{\mathrm{a}, \mathrm{b}}$ & Wild type & 13761 & 72 & $\mathrm{M}$ & NA & $\mathrm{NE}$ & $22.7^{\mathrm{c}}$ & $\begin{array}{l}\text { Cardiac failure, } \\
\text { sepsis }\end{array}$ & $\begin{array}{l}\text { Combined patchy deposits (diffuse } \\
\text { pericellular deposition) }\end{array}$ \\
\hline B-case $6^{\mathrm{b}}$ & Wild type & 13761 & 73 & $\mathrm{M}$ & NA & $5.0^{\mathrm{c}}$ & $13.6^{\mathrm{c}}$ & Alive & Patchy plaque-like shape (moderate) \\
\hline B-case $7^{\mathrm{b}}$ & Wild type & 13761 & 74 & M & NA & $\mathrm{NE}$ & $10^{\mathrm{c}}$ & Alive & Patchy plaque-like shape (small) \\
\hline B-case $8^{\mathrm{b}}$ & Wild type & 13761 & 75 & M & NA & $\mathrm{NE}$ & $11.4^{\mathrm{c}}$ & Alive & $\begin{array}{l}\text { Patchy plaque-like shape (moderate } \\
\text { to large) }\end{array}$ \\
\hline B-case $9^{b}$ & Wild type & 13761 & 76 & M & NA & $\mathrm{NE}$ & $10.4^{\mathrm{c}}$ & Alive & Patchy plaque-like shape (moderate) \\
\hline B-case $10^{\mathrm{b}}$ & Wild type & 13761 & 83 & M & NA & $\mathrm{NE}$ & $14.4^{\mathrm{c}}$ & Alive & $\mathrm{NE}$ \\
\hline B-case $11^{\mathrm{b}}$ & Wild type & 13761 & 85 & $\mathrm{M}$ & NA & $\mathrm{NE}$ & $15.1^{\mathrm{C}}$ & Alive & $\mathrm{NE}$ \\
\hline Average & & & 73.1 & & 5.0 & 15.4 & & & \\
\hline S.d. & & & 7.6 & & NA & 5.0 & & & \\
\hline \multicolumn{10}{|c|}{ Familial amyloidotic polyneuropathy (autopsied cases) } \\
\hline F-case $1^{\mathrm{d}}$ & V30M & $13761 / 13793$ & 42 & $\mathrm{~F}$ & 320 & 7 & 17 & Sudden death & $\begin{array}{l}\text { Deposits in pericardial border and } \\
\text { surrounding muscle fascicles }\end{array}$ \\
\hline F-case $2^{\mathrm{d}}$ & Y114C & $13701 / 13761$ & 53 & $\mathrm{~F}$ & 580 & 15 & 25 & Sudden death & $\begin{array}{l}\text { Deposits in border area surrounding } \\
\text { muscle fascicles, and severe deposits in } \\
\text { vascular walls }\end{array}$ \\
\hline F-case $3^{\mathrm{d}}$ & S50I & $13761 / 13781$ & 54 & $\mathrm{M}$ & 570 & $\mathrm{NE}$ & $\mathrm{NE}$ & Cardiac failure & Severe diffuse pericellular deposition \\
\hline F-case $4^{\mathrm{d}}$ & V30M & $13761 / 13793$ & 67 & M & 438 & $\mathrm{NE}$ & 20 & Cardiac failure & $\begin{array}{l}\text { Deposits in pericardial border and } \\
\text { surrounding muscle fascicles }\end{array}$ \\
\hline
\end{tabular}


of amyloid deposits in the body, available other tissue specimens of those senile systemic amyloidosis and familial amyloidotic polyneuropathy cases were also examined (Table 2, and Supplementary Table S2).

Furthermore, to determine ante-mortem clinicopathological findings of senile systemic amyloidosis, we also studied 11 senile systemic amyloidosis patients who were diagnosed at Kumamoto University Hospital, Department of Cardiology from January 2005 to December 2010.

\section{Congo Red Staining}

Tissue samples were embedded in paraffin, serially sectioned at a thickness of $4 \mu \mathrm{m}$, and placed on microscope slides. Sections were stained with hematoxylin-eosin and alkaline Congo red and were also examined under polarized light for the presence of green birefringence. The degree of amyloid deposition was determined by computer measurement of Congo red-positive areas via the public domain Image program developed by the US National Institutes of Health and available at http://rsb.info.nih.gov/ij/index.html, as described previously. ${ }^{16}$ For each cardiac specimen, three different visual fields were studied at $\times 100$ magnification, and pictures were saved via a digital camera (Olympus DP70; Olympus, Tokyo, Japan).

\section{Electron Microscopy}

Post-mortem cardiac samples were fixed first in $4 \%$ paraformaldehyde and 1\% glutaraldehyde solution and then in $1 \% \mathrm{OsO}_{4}$, after which they were embedded in Epon. Ultrathin sections were stained with $4 \%$ uranyl acetate and lead citrate and were examined with a transmission electron microscope (H-7500; Hitachi, Tokyo, Japan) at an accelerating voltage of $100 \mathrm{kV}$, as described previously. ${ }^{17}$

\section{Immunohistochemistry}

To clarify the types of amyloid proteins, cardiac specimens with amyloid deposits were stained with antibodies that react with transthyretin, atrial natriuretic factor, immunoglobulin light chain (lambda and kappa), amyloid $\mathrm{A}$, and $\beta_{2}$-microglobulin (Supplementary Table S1), as described previously. ${ }^{16}$ To show morphological features of the ventricle as a whole, we also created a joint image with the image stitching function of the BZ-8100 microscope (Keyence, Osaka, Japan), which can join high-resolution images into a single wide-field image.

\section{Genetic and Mass Spectrometric Analyses for Detecting Transthyretin Mutations}

PCR amplification by direct DNA sequencing was accomplished with the use of ABI BigDye 
Table 2 Presence of amyloid deposits in various tissues from six autopsied senile systemic amyloidosis cases

\begin{tabular}{|c|c|c|c|c|c|c|c|c|}
\hline & $\begin{array}{c}A \text {-case } 1 \\
\text { (73 years) }\end{array}$ & $\begin{array}{c}\text { A-case } 2 \\
\text { (73 years) }\end{array}$ & $\begin{array}{c}A \text {-case } 3 \\
\text { (75 years) }\end{array}$ & $\begin{array}{c}A \text {-case } 4 \\
\text { (83 years) }\end{array}$ & $\begin{array}{c}\text { A-case } 5 \\
\text { (93 years) }\end{array}$ & $\begin{array}{c}A \text {-case } 6 \\
\text { (102 years) }\end{array}$ & $\begin{array}{l}\% \text { Positive samples } \\
\text { including vascular } \\
\text { deposits (no./total no.) }\end{array}$ & $\begin{array}{c}\% \text { Deposits in extracellular } \\
\text { interstitium } \\
\text { (no./total no.) }\end{array}$ \\
\hline \multicolumn{9}{|l|}{ Heart } \\
\hline Left ventricle & + & +++ & +++ & ++ & + & +++ & $100(6 / 6)$ & $100(6 / 6)$ \\
\hline Right ventricle & - & +++ & +++ & + & NE & $\mathrm{NE}$ & $75(3 / 4)$ & $75(3 / 4)$ \\
\hline Interventricular septum & + & $\mathrm{NE}$ & +++ & $\mathrm{NE}$ & + & $\mathrm{NE}$ & $100(3 / 3)$ & $100(2 / 2)$ \\
\hline Left atrium & - & $\mathrm{NE}$ & +++ & $\mathrm{NE}$ & NE & $\mathrm{NE}$ & $50(1 / 2)$ & $50(1 / 2)$ \\
\hline Right atrium & - & $\mathrm{NE}$ & +++ & NE & $\mathrm{NE}$ & NE & $50(1 / 2)$ & $50(1 / 2)$ \\
\hline \multicolumn{9}{|l|}{ Artery } \\
\hline Aorta & - & + & + & $\mathrm{v}+$ & + & $\mathrm{NE}$ & $80(4 / 5)$ & $60(3 / 5)$ \\
\hline Coronary artery & - & NE & - & - & NE & - & $0(0 / 4)$ & $0(0 / 4)$ \\
\hline Common carotid artery & - & NE & + & NE & NE & NE & $50(1 / 2)$ & $50(1 / 2)$ \\
\hline Renal artery & - & $\mathrm{NE}$ & ++ & - & + & $\mathrm{NE}$ & $50(2 / 4)$ & $50(2 / 4)$ \\
\hline Lung & + & +++ & +++ & + & ++ & ++ & $100(6 / 6)$ & $100(6 / 6)$ \\
\hline Tongue & NE & $\mathrm{v}+$ & ++ & $\mathrm{NE}$ & $\mathrm{v}+$ & $\mathrm{NE}$ & $100(3 / 3)$ & $33(1 / 3)$ \\
\hline Esophagus & - & $\mathrm{v}+$ & + & - & $\mathrm{v}+$ & NE & $60(3 / 5)$ & $20(1 / 5)$ \\
\hline Stomach & - & $\mathrm{v}+$ & + & $\mathrm{v}+$ & + & $\mathrm{NE}$ & $80(4 / 5)$ & $40(2 / 5)$ \\
\hline Duodenum & - & $\mathrm{NE}$ & + & $\mathrm{NE}$ & $\mathrm{v}+$ & $\mathrm{v}+$ & $75(3 / 4)$ & $25(1 / 4)$ \\
\hline Jejunum & - & $\mathrm{v}+$ & $\mathrm{v}+$ & + & $\mathrm{v}+$ & $\mathrm{NE}$ & $80(4 / 5)$ & $20(1 / 5)$ \\
\hline Ileum & - & $\mathrm{v}+$ & $\mathrm{v}+$ & $\mathrm{v}+$ & $\mathrm{v}+$ & NE & $80(4 / 5)$ & $0(0 / 5)$ \\
\hline Colon & - & $\mathrm{v}+$ & $\mathrm{v}+$ & $\mathrm{v}+$ & $\mathrm{v}+$ & NE & $80(4 / 5)$ & $0(0 / 5)$ \\
\hline Rectum & - & $\mathrm{v}+$ & $\mathrm{v}+$ & $\mathrm{v}+$ & NE & $\mathrm{NE}$ & $75(3 / 4)$ & $0(0 / 4)$ \\
\hline Liver & - & - & $\mathrm{v}+$ & - & $\mathrm{v}+$ & $\mathrm{NE}$ & $40(2 / 5)$ & $0(0 / 5)$ \\
\hline Gallbladder & - & $\mathrm{v}+$ & $\mathrm{v}+$ & + & NE & NE & $75(3 / 4)$ & $25(1 / 4)$ \\
\hline Kidney & - & - & + & - & $\mathrm{v}+$ & $\mathrm{NE}$ & $40(2 / 5)$ & $20(1 / 5)$ \\
\hline Glomerulus & - & - & - & - & - & NE & $0(0 / 5)$ & $0(0 / 5)$ \\
\hline Adrenal gland & - & $\mathrm{NE}$ & $\mathrm{v}+$ & $\mathrm{v}+$ & $\mathrm{v}+$ & $\mathrm{NE}$ & $75(3 / 4)$ & $0(0 / 4)$ \\
\hline Ureter & $\mathrm{NE}$ & NE & + & $\mathrm{v}+$ & NE & $\mathrm{NE}$ & $100(2 / 2)$ & $50(1 / 2)$ \\
\hline Bladder & - & + & + & + & + & NE & $80(4 / 5)$ & $80(4 / 5)$ \\
\hline Prostate & - & + & $\mathrm{v}+$ & NA & $\mathrm{NE}$ & NA & $67(2 / 3)$ & $33(1 / 3)$ \\
\hline Testis & - & - & - & NA & NE & NA & $0(0 / 3)$ & $0(0 / 3)$ \\
\hline Uterus & NA & NA & NA & $\mathrm{v}+$ & NA & $\mathrm{NE}$ & $100(1 / 1)$ & $0(0 / 1)$ \\
\hline Thyroid gland & - & $\mathrm{v}+$ & $\mathrm{v}+$ & NE & $\mathrm{v}+$ & $\mathrm{NE}$ & $75(3 / 4)$ & $0(0 / 4)$ \\
\hline Pancreas & - & $\mathrm{v}+$ & $\mathrm{v}+$ & - & $\mathrm{v}+$ & NE & $60(3 / 5)$ & $0(0 / 5)$ \\
\hline Spleen & - & $\mathrm{v}+$ & - & $\mathrm{NE}$ & $\mathrm{NE}$ & $\mathrm{NE}$ & $33(1 / 3)$ & $0(0 / 3)$ \\
\hline Spinal ligament & $\mathrm{NE}$ & NE & +++ & $\mathrm{NE}$ & NE & $\mathrm{NE}$ & $100(1 / 1)$ & $100(1 / 1)$ \\
\hline Bone marrow & - & - & - & NE & - & $\mathrm{NE}$ & $0(0 / 4)$ & $0(0 / 4)$ \\
\hline
\end{tabular}

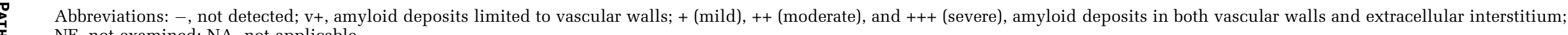
NE, not examined; NA, not applicable.

Patients' profiles were described in Table 1. 
Terminator reagents (Applied Biosystems, Foster City, CA, USA) on the 3130 Genetic Analyzer (Applied Biosystems). We processed the transthyretin gene by using DNA prepared from peripheral blood leukocytes or paraffin-embedded formalinfixed specimens with the following specific primers: exon 1 forward: $5^{\prime}$-TCAGATTGGCAGGGATAAGC- ${ }^{\prime}$, reverse: $5^{\prime}$-GCAAAGCTGGAAGGAGTCAC-3'; exon 2 forward: $5^{\prime}$-CGTTCCTGATAATGGGATCA-3' ${ }^{\prime}$, reverse: 5'-CAAAAAGAGGGCATCCTTCA-3'; exon 3 forward: $5^{\prime}$-TCTGACTTAGTTGAGGGGAAATG-3', reverse: $5^{\prime}$-AGGGAACCTTTGGTCATTCA-3'; exon 4 forward: $5^{\prime}$-TGCCAGCATATTTGAGCTTTTT-3' ${ }^{\prime}$, reverse: $5^{\prime}$-AT GAAAAGTGCCTTTCACAGGA- $3^{\prime}$.

To measure the molecular mass of serum transthyretin, we performed mass spectrometric analyses with surface-enhanced laser desorption/ionization time-of-flight mass spectrometry (SELDI-TOF MS; PCS 4000 SELDI-TOF MS instrument; Bio-Rad, Hercules, CA, USA), as previously described..$^{18}$

\section{Ethics}

The Human Ethics Review Committee of Kumamoto University approved the study protocol, and signed consent forms were obtained from families of subjects. All patients' family members gave informed consent for performance of an autopsy.

\section{Statistical Analysis}

Data were evaluated with Student's $t$-test and ANOVA. All analyses were performed with JMP version 5.1 (SAS Institute Japan, Tokyo, Japan). $P$-values of $<0.05$ were regarded as statistically significant.

\section{Results}

All cardiac tissues examined from 48 of 181 (27\%) autopsied cases showed amyloid deposits. We determined the occurrence of cardiac amyloidosis in each generation older than 40-year old (Supplementary Figure S1). As shown in Figure 1, we determined types of cardiac amyloidosis by means of the immunohistochemical stainings. To distinguish senile systemic amyloidosis from familial amyloidotic polyneuropathy, we analyzed the transthyretin gene sequence and/or the shift in molecular mass of transthyretin in all cases with transthyretin amyloid deposits (Figure 2, Table 1). The occurrence of senile systemic amyloidosis in elderly Japanese cases (older than 80 years) was $11.5 \%(3 / 26)$ and increased with age (Figure 1). Of the 181 autopsied cases, none younger than 70 years showed evidence of senile systemic amyloidosis.

In this study, we also evaluated clinicopathological findings for autopsied cases and ante-mortem biopsied cases of senile systemic amyloidosis and
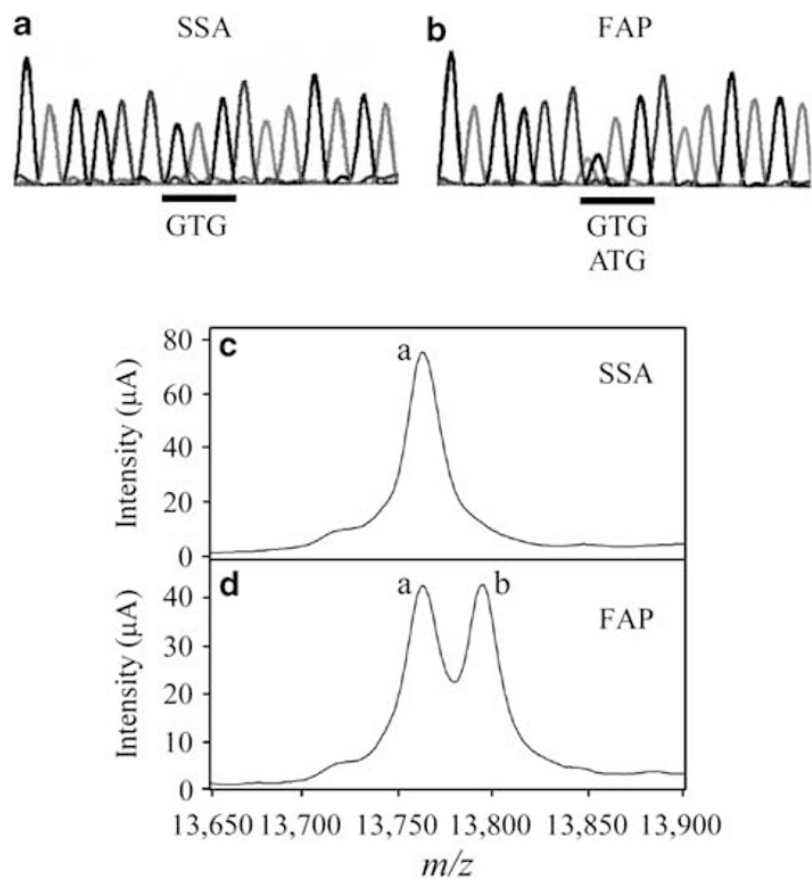

Figure 2 Detection of variant transthyretins by means of genetic and protein analyses. Transthyretin DNA sequences were examined for senile systemic amyloidosis (a) and familial amyloidotic polyneuropathy (b) by using ABI BigDye Terminator reagents. A heterozygous transversion of $\mathrm{G}$ to $\mathrm{A}$ was predicted to change valine to methionine at residue 30 of the mature protein (Val30Met) (underlined). Mass spectrometric analysis of transthyretin from serum samples of senile systemic amyloidosis (c) and familial amyloidotic polyneuropathy (d) cases was performed by means of the PCS 4000 SELDI-TOF MS instrument. (a) Wild-type transthyretin (13761 Da); (b) mutant transthyretin Val30Met (13 $793 \mathrm{Da})$.

autopsied cases of familial amyloidotic polyneuropathy (Table 1). A significant difference in age was observed for the senile systemic amyloidosis and familial amyloidotic polyneuropathy autopsied cases $(83.2 \pm 12.0$ years versus $57.8 \pm 12.3$ years, respectively, $P<0.01$ ), but no significant difference in LV thickness or heart weight was found (Table 1). Three of autopsied senile systemic amyloidosis cases (3/6) died of cardiac failure, which is the main clinical feature of senile systemic amyloidosis. In addition, one of those senile systemic amyloidosis cases died of interstitial pneumonia with pulmonary hemorrhage.

Figure 3 clearly shows differences in the morphology of cardiac transthyretin amyloid deposits in senile systemic amyloidosis and familial amyloidotic polyneuropathy. Transthyretin amyloid deposits developed predominantly in the pericardium and surrounding muscle fascicles in familial amyloidotic polyneuropathy, whereas they appeared as patchy plaque-like shapes and developed predominantly inside the ventricular wall in senile systemic amyloidosis (Figures 3a-i, Table 1). Electron microscopic examination revealed differences in morphology of amyloid fibrils in greater detail 

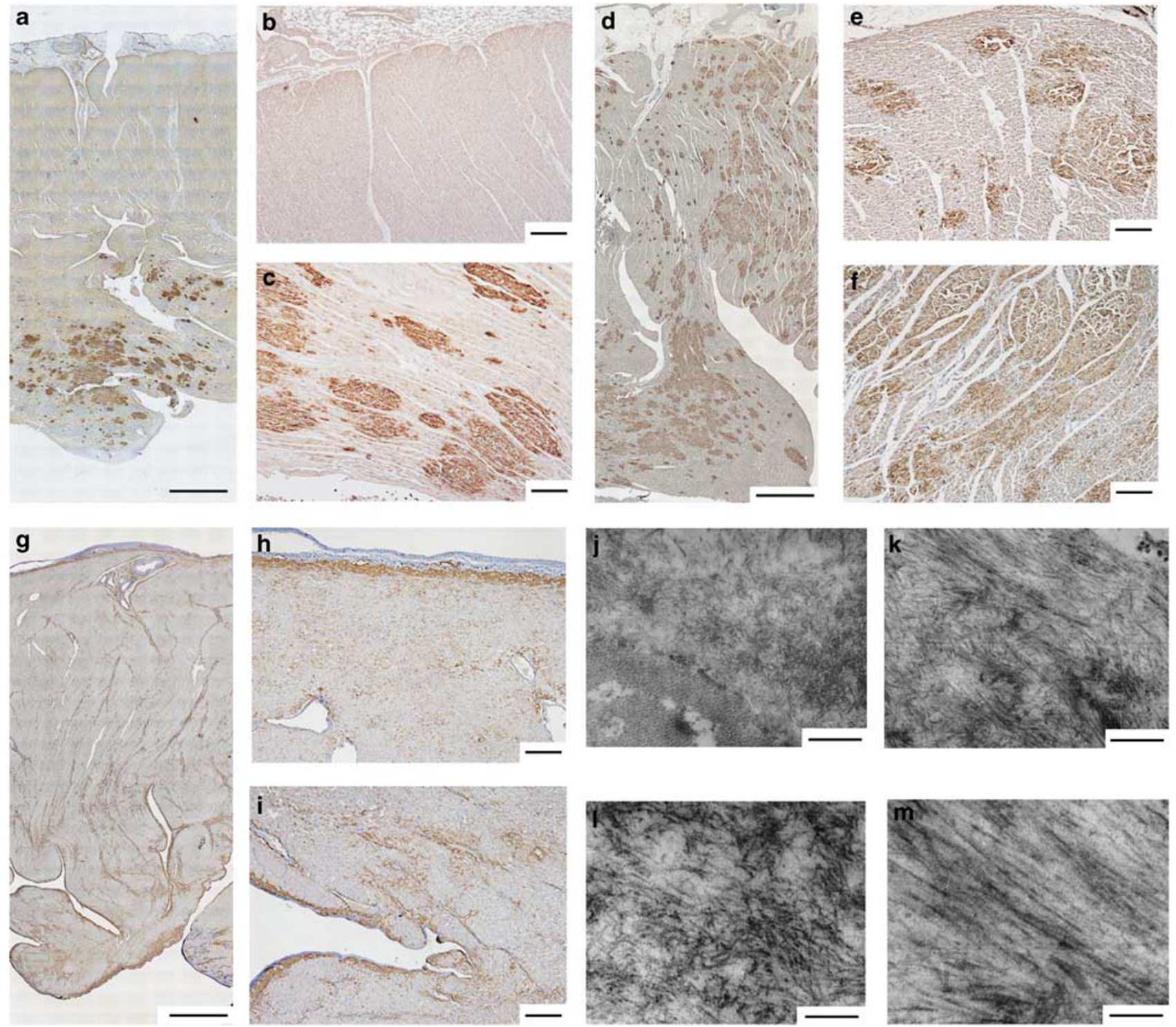

Figure 3 Morphological features of cardiac transthyretin amyloid deposits in senile systemic amyloidosis and familial amyloidotic polyneuropathy, which demonstrate a major difference between these disorders. (a-i) Immunohistochemical staining with an antitransthyretin antibody (Dako). (a-f) Patchy plaque-like deposits in the ventricles of senile systemic amyloidosis cases (a-c: A-case 4, d-f: A-case 2). (g-i) Deposits in the pericardial border and surrounding muscle fascicles in the ventricle of an familial amyloidotic polyneuropathy patient (F-case 4). (b, e, h) Epicardial side of the left ventricular wall. (c, f, i) Endocardial side of the left ventricular wall. (a, d, g) Joint images created with the image stitching function of the BZ-8100 microscope (Keyence); scale bars: $3 \mathrm{~mm}$. (b, c, e, f, h, i) Scale bars: $200 \mu \mathrm{m}$. (j-m) Electron micrographs of amyloid fibrils in cardiac specimens. (j, l) Short, rigid, haphazardly arranged fibrils in senile systemic amyloidosis (A-case 3). (k, m) Long, straight, parallel fibrils in familial amyloidotic polyneuropathy transthyretin Val30Met (F-case 4). (j, k) Scale bars: $500 \mathrm{~nm}$. (l, m) Scale bars: $200 \mathrm{~nm}$.

(Figures 3j-m): long, straight fibrils were arranged in parallel in familial amyloidotic polyneuropathy, whereas short, rigid fibrils were haphazardly arranged in senile systemic amyloidosis. In all senile systemic amyloidosis cases, the endocardial side of the left ventricular wall had larger areas of amyloid deposits than did the epicardial side of the left ventricular wall (Figure 4).

We also investigated the distribution of transthyretin amyloid deposits in various tissues in autopsied senile systemic amyloidosis cases (Table 2) and familial amyloidotic polyneuropathy (Supplementary Table S2). Amyloid deposits occurred in the left ventricle and lungs of all these senile systemic amyloidosis cases (6/6). Amyloid deposits were also observed in the 5/6 cases of the bladder (Table 2). In thyroid gland, pancreas, liver, gallbladder, adrenal gland, and gastrointestinal tract, they were detected predominantly in the walls of small arteries (Table 2). In the gastrointestinal tract of familial amyloidotic polyneuropathy cases, amyloid deposits were found both in basal laminae and in walls of 
small arteries (Figure 5, Supplementary Table S2). However, in senile systemic amyloidosis cases, amyloid deposits were detected predominantly in walls of small arteries (Figure 5, Table 2). Furthermore, in the glomerulus of kidney, all of familial amyloidotic polyneuropathy cases (5/5) showed amyloid deposits (Supplementary Table S2), but none of senile systemic amyloidosis cases developed amyloid deposits (Table 2). One senile systemic amyloidosis case (A-case 3) also evidenced

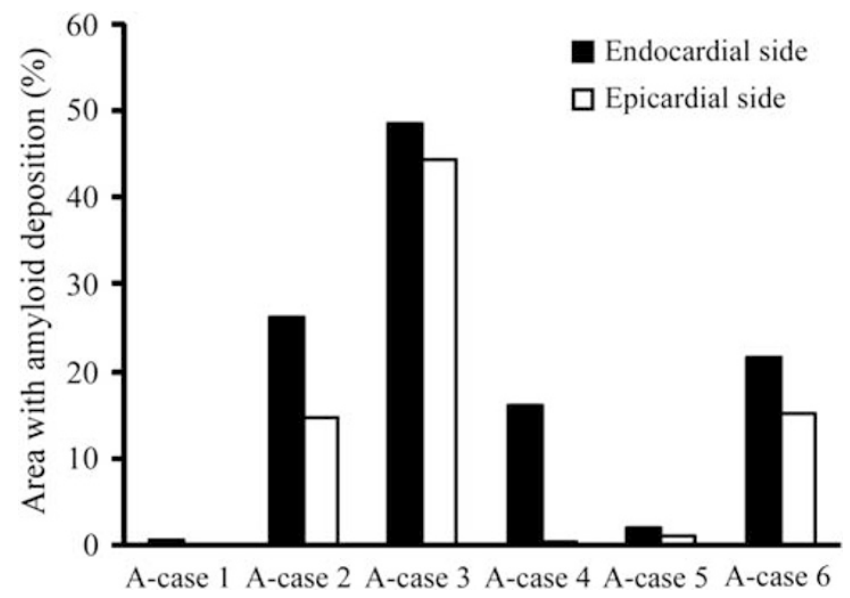

Figure 4 Areas with amyloid deposits in the endocardial and epicardial sides of the left ventricular wall in autopsied senile systemic amyloidosis cases. Areas with amyloid deposition were measured as described in the text. severe amyloid deposits in spinal ligaments (Supplementary Figure S2).

Transthyretin amyloid deposits were detected in $100 \%$ (8/8) of myocardial samples obtained from senile systemic amyloidosis patients who had antemortem biopsies (Table 3). However, much less amyloid was detected in the gastrointestinal tract and subcutaneous tissue than in the myocardium. Analysis of both gastrointestinal tract and subcutaneous tissues combined indicated amyloid deposits in $44.4 \%(4 / 9)$ of senile systemic amyloidosis patients (Table 3 ).

One of those patients (B-case 11) showed a nodular transthyretin amyloid deposit mimicking a lung cancer mass (Figure 6a). A lung biopsy revealed that the mass lesion consisted of severe transthyretin amyloid deposits without malignant cells (Figures 6b-d).

\section{Discussion}

In this report, we investigated the clinicopathological features of senile systemic amyloidosis in elderly Japanese patients by means of post-mortem and ante-mortem studies. We also demonstrated major histopathological differences between senile systemic amyloidosis and familial amyloidotic polyneuropathy.

In studies of post-mortem specimens, we determined that the occurrence of senile systemic amyloidosis in elderly Japanese cases (older than
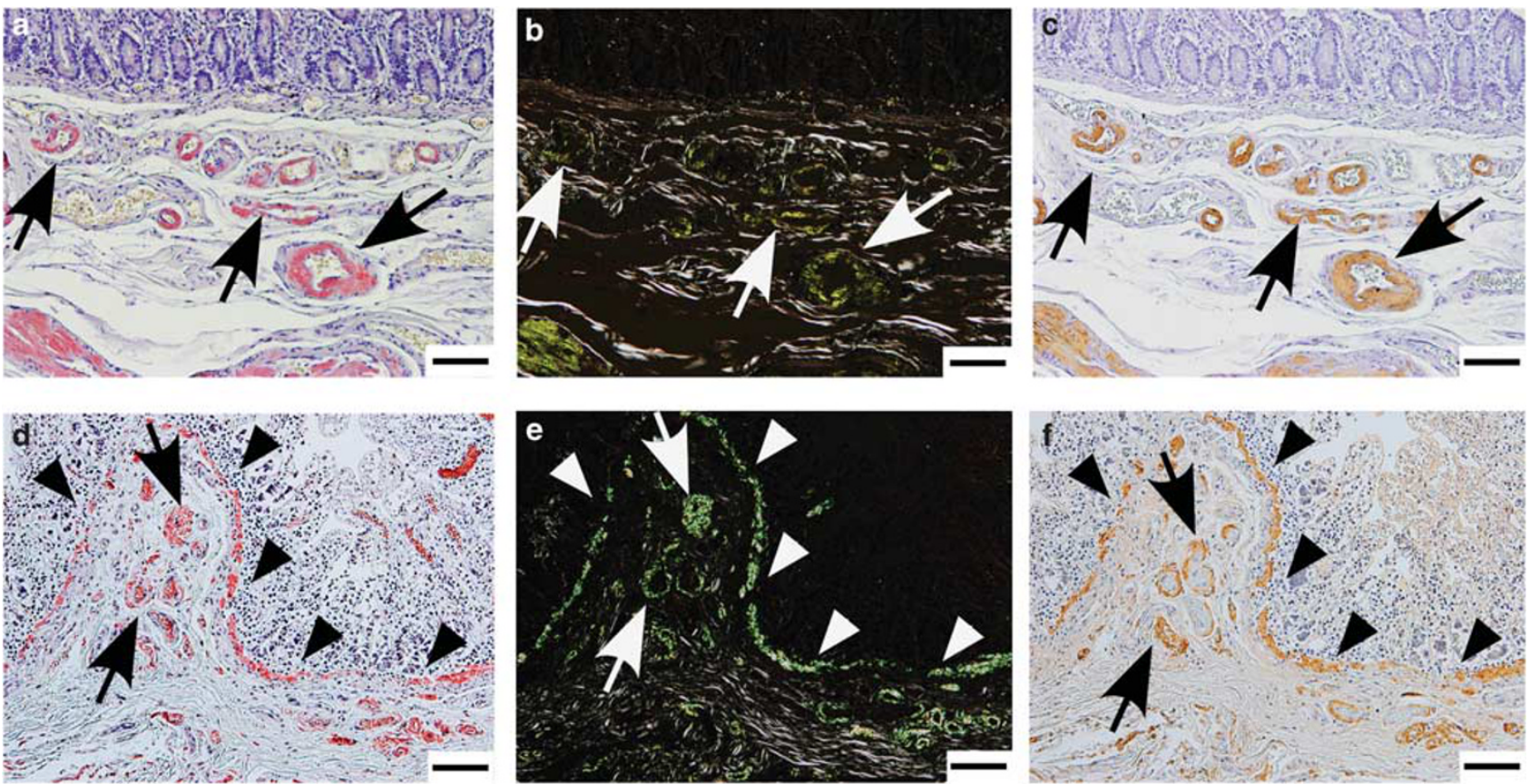

Figure 5 Transthyretin amyloid deposits in the duodenum: major differences between senile systemic amyloidosis and familial amyloidotic polyneuropathy. (a-c) Senile systemic amyloidosis (A-case 3). (d-f) Familial amyloidotic polyneuropathy (F-case 4). (a, d) Congo red staining, (b, e) Congo red staining viewed under polarized light, and (c, f) immunohistochemical staining using an antitransthyretin antibody. Arrows point to vascular amyloid deposits; arrowheads, to amyloid deposits in the basal laminae. Scale bars: $200 \mu \mathrm{m}$. 


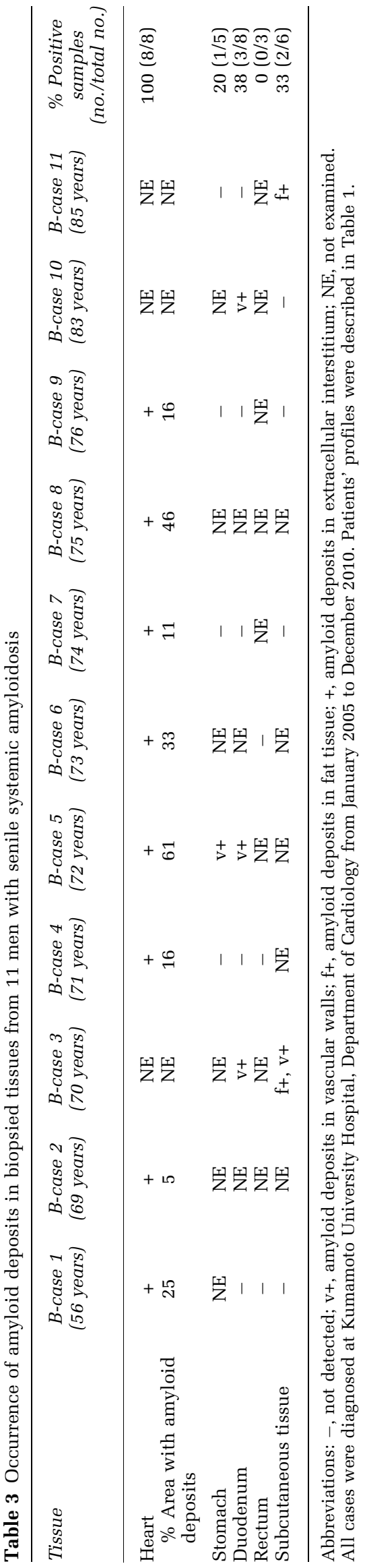

80 years) was $11.5 \%$, which was lower than in cases investigated by the same means in the United States and European countries (22-25\%). ${ }^{7-9}$ Although we did not identify the reasons for this difference, we suspect that genetic and/or environmental factors may affect the occurrence of the disease. However, as Table 1 shows almost all senile systemic amyloidosis patients (5/6), except for A-case 3, had never been diagnosed as having senile systemic amyloidosis, although two of those patients $(2 / 5)$ died of cardiac failure, which is the main clinical feature of senile systemic amyloidosis. This finding indicates that more attention should be paid to senile systemic amyloidosis when evaluating and diagnosing cardiac failure in the elderly.

For these same post-mortem senile systemic amyloidosis cases, we provided detailed histopathological findings of amyloid deposits in various organs. Several post-mortem studies of senile systemic amyloidosis have been reported,,$^{5,7,19,20}$ but our careful study elucidated specific histopathological features of senile systemic amyloidosis in various systemic tissues. We also demonstrated major histopathological differences, including the distribution of amyloid deposits in various organs and the morphological features of amyloid fibrils in cardiac specimens, between senile systemic amyloidosis and mutant transthyretin-derived familial amyloidotic polyneuropathy. These results suggest that the amyloid formation mechanisms in familial amyloidotic polyneuropathy and senile systemic amyloidosis may differ. Bergström et $a l^{21}$ reported finding morphologically different amyloid fibrils in cardiac specimens from Swedish patients with senile systemic amyloidosis and those with familial amyloidotic polyneuropathy: short, rigid, haphazardly arranged fibrils predominantly in senile systemic amyloidosis, and long, straight, parallel fibrils in familial amyloidotic polyneuropathy. They proposed that fragmentation of C-terminal portions of transthyretin in senile systemic amyloidosis may generate the different amyloid fibrils. In fact, our electron microscopic findings were consistent with data from their studies of Swedish patients.

We also demonstrated different organ distributions of amyloid deposits in post-mortem senile systemic amyloidosis cases compared with distributions previously reported for Japanese familial amyloidotic polyneuropathy patients. ${ }^{22}$ We found that amyloid deposits in senile systemic amyloidosis tended to develop predominantly in tissues with high mechanical stress, such as the cardiac ventricle (especially the endocardial side), alveolar wall of the lungs, bladder wall, and vascular walls, but they rarely developed in tissues without such mechanical stress, such as the glomerulus and thyroid gland, where severe amyloid deposits were often found in familial amyloidotic polyneuropathy (Supplementary Table S2). ${ }^{22}$ In addition, we also discovered severe amyloid deposits in the spinal ligaments of a post-mortem senile systemic 

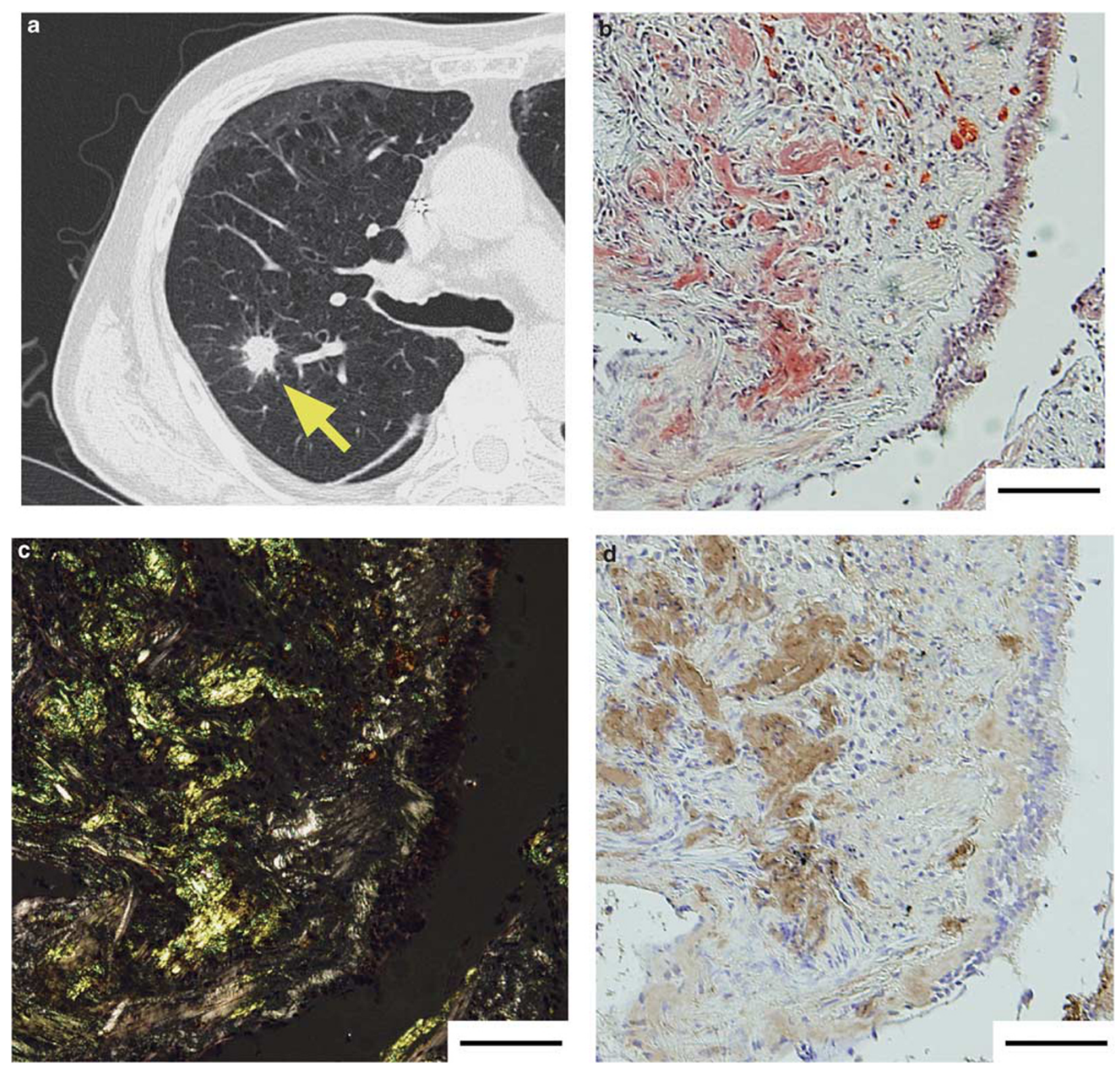

Figure 6 Nodular lesion in the lung of SSA. (a) Chest CT showed a nodular lesion (arrow) mimicking a tumor in the lung of a SSA patient B-case 11. (b-d) Microscopic biopsy findings. (b) Congo red staining, (c) Congo red staining viewed under polarized light, and (d) immunohistochemical staining using an anti-TTR antibody. Scale bars: $200 \mu \mathrm{m}$.

amyloidosis case (Supplementary Figure S2). We recently demonstrated wild-type transthyretinderived amyloid deposits in $35 \%$ (39/111 cases) of surgically resected ligaments from patients older than 40 years with orthopedic disorders. ${ }^{23}$ Amyloid deposits in such ligaments of senile systemic amyloidosis patients may frequently develop without obvious symptoms. On the basis of those findings, we speculate that aging of the tissue matrix caused by long-term mechanical stress may have an important role in amyloid formation in senile systemic amyloidosis. Additional studies are needed to confirm this possibility.
In addition, we found a nodular transthyretin amyloid deposit that mimicked a cancer lesion in the lung of a senile systemic amyloidosis patient (Figure 6). This type of amyloid deposit in senile systemic amyloidosis lungs has not been described except for one account in a case report. ${ }^{24}$ Furthermore, in post-mortem autopsied cases, one senile systemic amyloidosis case (A-case 2) died of interstitial pneumonia and pulmonary hemorrhage (Table 1) with severe transthyretin amyloid deposits in lungs (Table 2). Those findings suggest that attention should be paid to such amyloid deposits in the lung, which is another major amyloid-targeted site. 
To obtain an accurate diagnosis of senile systemic amyloidosis, confirmation of the presence of transthyretin amyloid deposits is needed by means of tissue biopsies of suitable organs. ${ }^{1,2}$ Although we observed amyloid deposits in the heart and lung of all senile systemic amyloidosis cases in our postmortem study, biopsies of these tissues are often difficult to perform because of the highly invasive biopsy methods needed. Although, in most of postmortem senile systemic amyloidosis cases (5/6), amyloid deposits were observed predominantly in the vascular walls in the gastrointestinal tract (Table 2), which is one of the most common biopsy sites used for diagnosis of various types of systemic amyloidosis because of the less invasive method required, ${ }^{1}$ we detected no amyloid deposits in the gastrointestinal tract of more than half of the ante-mortem senile systemic amyloidosis patients (Table 3). These results suggest that amyloid deposits in the gastrointestinal tract may develop in early stages of senile systemic amyloidosis. In addition, we found no amyloid in the basal laminae in the gastrointestinal tract, a site where amyloid deposits often developed in familial amyloidotic polyneuropathy (Figure 5, Supplementary Table S2). These histopathological findings lead to the conclusion that diagnosis of senile systemic amyloidosis requires obtaining a biopsy specimen from deeper sites containing submucosal vascular walls of the tract rather than using the common biopsy method. Moreover, biopsy of subcutaneous tissue may help detect transthyretin amyloid deposits, because one senile systemic amyloidosis patient (B-case 11) evidenced amyloid deposits in subcutaneous fat but not in the gastrointestinal tract (Table 3).

In conclusion, we provide here the first data showing the occurrence of senile systemic amyloidosis in an elderly Japanese population. The lower occurrence of amyloid deposition suggests differences in genetic and/or environmental factors. We also believe that our detailed clinicopathological findings for systemic tissues will provide novel insights into understanding senile systemic amyloidosis.

\section{Acknowledgements}

We thank Hiroko Katsura for her technical support during histopathological investigations. The authors' work were partially supported by a Grant-in-Aid for Scientific Research (B) 21253742 (Y Ando) and by Grants-in-Aid for Young Scientists (B) 21404337 (Y Horibata) and 21790541 (M Ueda) from the Ministry of Labour, Education, Science, Sports and Culture of Japan, and by a Research grant (M Ueda) from the Kurozumi Medical Foundation.

\section{Disclosure/conflict of interest}

The authors declare no conflict of interest.

\section{References}

1 Merlini G, Westermark P. The systemic amyloidoses: clearer understanding of the molecular mechanisms offers hope for more effective therapies. J Intern Med 2004;255:159-178.

2 Benson MD. Amyloidosis. In: Koopman WJ (ed). Arthritis and Allied Conditions, A Textbook of Rheumatology, 14th edn. Lippincott Williams and Wilkins: Philadelphia, 2001, pp 1866-1895.

3 Cummings JL. Toward a molecular neuropsychiatry of neurodegenerative diseases. Ann Neurol 2003;54: 147-154.

4 Sipe JD, Benson MD, Buxbaum JN, et al. Amyloid fibril protein nomenclature: 2010 recommendations from the nomenclature committee of the International Society of Amyloidosis. Amyloid 2010;17:101-104.

5 Westermark P, Bergström J, Solomon A, et al. Transthyretin-derived senile systemic amyloidosis: clinicopathologic and structural considerations. Amyloid 2003;10:48-54.

6 Rapezzi C, Quarta CC, Riva L, et al. Transthyretinrelated amyloidoses and the heart: a clinical overview. Nat Rev Cardiol 2010;7:398-408.

7 Cornwell III GG, Murdoch WL, Kyle RA, et al. Frequency and distribution of senile cardiovascular amyloid. A clinicopathologic correlation. Am J Med 1983;75:618-623.

8 Westermark P, Johansson B, Natvig JB. Senile cardiac amyloidosis: evidence of two different amyloid substances in the ageing heart. Scand J Immunol 1979;10:303-308.

9 Tanskanen M, Peuralinna T, Polvikoski T, et al. Senile systemic amyloidosis affects $25 \%$ of the very aged and associates with genetic variation in alpha2-macroglobulin and tau: a population-based autopsy study. Ann Med 2008;40:232-239.

10 Ando Y, Nakamura M, Araki S. Transthyretin-related familial amyloidotic polyneuropathy. Arch Neurol 2005;62:1057-1062.

11 Benson MD, Kincaid JC. The molecular biology and clinical features of amyloid neuropathy. Muscle Nerve 2007;36:411-423.

12 Connors LH, Lim A, Prokaeva T, et al. Tabulation of human transthyretin variants, 2003. Amyloid 2003;10:160-185.

13 Jacobson DR, Pastore RD, Yaghoubian R, et al. Variantsequence transthyretin (isoleucine 122) in late-onset cardiac amyloidosis in black Americans. N Engl J Med 1997;336:466-473.

14 Coelho T, Maia L, Martins A, et al. Tafamidis (Fx-1006A): a first-in-class disease-modifying therapy for transthyretin familial amyloid. Proceedings of the XII International Symposium on Amyloidosis, 18-21 April 2010; Rome, Italy. International Society of Amyloidosis: Rome, 2010.

15 Hammarström P, Schneider F, Kelly JW. Trans-suppression of misfolding in an amyloid disease. Science 2001;293:2459-2462.

16 Ueda M, Ando Y, Nakamura M, et al. FK506 inhibits murine AA amyloidosis. Possible involvement of $\mathrm{T}$ cells in amyloidogenesis. J Rheumatol 2006;33: 2260-2270.

17 Misumi Y, Ando Y, Ueda M, et al. Chain reaction of amyloid fibril formation with induction of basement membrane in familial amyloidotic polyneuropathy. J Pathol 2009;219:481-490. 
18 Ueda M, Misumi Y, Mizuguchi M, et al. SELDITOF MS evaluation of variant transthyretins for diagnosis and pathogenesis of familial amyloidotic polyneuropathy. Clin Chem 2009;55:1223-1227.

19 Pitkänen P, Westermark P, Cornwell III GG. Senile systemic amyloidosis. Am J Pathol 1984;117:391-399.

20 Strege RJ, Saeger W, Linke RP. Diagnosis and immunohistochemical classification of systemic amyloidoses. Report of 43 cases in an unselected autopsy series. Virchows Arch 1998;433:19-27.

21 Bergström J, Gustavsson A, Hellman U, et al. Amyloid deposits in transthyretin-derived amyloidosis: cleaved transthyretin is associated with distinct amyloid morphology. J Pathol 2005;206:224-232.
22 Takahashi K, Yi S, Kimura Y, et al. Familial amyloidotic polyneuropathy type 1 in Kumamoto, Japan: a clinicopathologic, histochemical, immunohistochemical, and ultrastructural study. Hum Pathol 1991;22: 519-527.

23 Sueyoshi $\mathrm{T}$, Ueda $\mathrm{M}$, Jono $\mathrm{H}$, et al. Wildtype transthyretin-derived amyloidosis in various ligaments and tendons. Hum Pathol; published online 18 February 2011 [e-pub ahead of print].

24 Roden AC, Aubry MC, Zhang K, et al. Nodular senile pulmonary amyloidosis: a unique case confirmed by immunohistochemistry, mass spectrometry, and genetic study. Hum Pathol 2010;41: 1040-1045.

Supplementary Information accompanies the paper on Modern Pathology website (http://www.nature.com/ modpathol) 